\title{
Computer Supported Design Studio
}

Gianfranco Carrara, Antonio Fioravanti and Gabriele Novembri Università degli Studi "La Sapienza", Italy.

Pio Luigi Brusasco, Luca Caneparo and Anna Maria Zorgno

Politecnico di Torino, Italy.

The paper presents the ongoing experimentation of a Computer Supported Design Studio (CSDS). CSDS is part of our continuing effort to integrate computer systems in the design studio. We recognize three corner stones to CSDS: memory, process and collaboration. They offer a framework for the interpretation of the pedagogical aspects of the teaching of architectural design in relation to the innovations produced by information technologies.

The theme of the ongoing CSDS is a railway station in Turin, Italy, to be incorporated in a reorganized rail transport system. The choice of this theme emphasizes the realistic simulation aspects of the studio, where technical problems at the intersection of multiple disciplines need to be interpreted from an architectural point of view. 


\section{Introduction}

From our point of view the effort to integrate computers and the Internet in the design studio is part of a broader aim: evolving the way the studios function, which ultimately relates to the pedagogy of architectural design. Of course, strictly speaking, this is as "pertinent" to computers as writing a book is to a word processor.

Students, practitioners and academics require us to deliver new skills in digital design media. Moreover students, practitioners and, sometimes, academics require us to rethink the teaching of architectural design with an awareness of the new broader capabilities opened up by digital technologies and the issues raised by the information society.

The paper presents the ongoing experimentation of a Computer Supported Design Studio (CSDS) between the Dipartimento di Architettura Tecnica e Tecnica Urbanistica, Università degli Studi "La Sapienza" in Rome and Dipartimento di Progettazione architettonica, Politecnico di Torino in Turin, Italy.

\section{What does computer supported design stu- dio do?}

Until now, the only way design could be taught was, either by allowing students to participate in a design project, or by having them develop the design. The first of the methods is apprenticeship; the second is that used by schools of architecture. It may perhaps be possible to introduce the first method in the Schools, but this would run counter to a two hundrectyear tradition, originating with the eighteenth century Academies. The pattern of the studio education can be defined in design exercise as simulation, educator role, graphic formulation, continuous teacher-student interaction (Cuff, 1991) (Schon, 1985).

- A design studio is a simulation: that is, it implies imagining a virtual transformation of an area, in the city, country or wherever, and is relatively free from any need to actually realize the project.

- The teachers' role is to reproduce real project conditions, to provide a method of working which will cover everything the students need to work on and learn during the design. Throughout the "guided design" she or he must help students to follow all the stages of a significant experience of design. 'The studio instructor will be their semester-long guide into mysteries of design. (...) In studio, students gather the individual instructor's method and Weltanshauung" (Cuff, 1991, p. 121\}.

- The design exercise is formulated graphically by means of documents, e.g. sketches, drawings, drafts or models.

- A key element of the studio method is continuous teacher-student interaction, direct commu nication between the teacher and the individual student or, at the most, a small group of students.

Since Academies, several institutions -Bauhaus, Hochschule für Gestaltung UIm- have reinterpreted and innovated the design studio tradition to face emerging pedagogical or design issues.

The goal of CSDS is finalizing innovation in information technology to support a pedagogical approach, which prepares for multidisciplinary approach, "best practices" from industry, handson experience in digital media, teamwork and concurrent design.

- 'In architecture, as in other professions today, the debate continues over the issues of specialization and generalist training." (Cuff, 1991, p. 258). CSDS approach is to challenge students in realistic design simulation, where they are requested to creative synthesizing at the intersection of several disciplines. While in the traditional studio punctual interaction with experts from several knowledge domains proves difficult; the Internet can support continuous access and interaction with experts of different disciplines.

- Internet links can be institutionalized or adthoc set to involve professors in various disciplines as well specialists from industry or practicians. This is 
an effective way to integrate "best practices" from industry in the studio.

- Computer-based collaboration exposes stu dents to hands-on experience in solving technical problems by means of teamwork. Students are challenged in digital media application in order to collaborate successfully. They acquire team design experience based on concurrent application of multiple disciplines through the design process.

The Computer Supported Design Studio has three main key elements: memory, process and collaboration.

\section{Memory}

Memory consists of the documents elaborated during the design studio: from its early stages to the final presentation. A good final design is not the whole pedagogical aim of the design stu dio: it's equally important to teach a methodology. This methodology is the outcome of contir uous revision and suggestion focused on the student's design exercises. Schon's theories (1987) (Argyris \& Schon, 1996) evidence the relation ships between the dialectical nature of design and the design media, the "materials", i.e. sketches, drawings. The memory collects over time the dialectical, graphical, formulation of design exercises.

During the studio the student develops several designsolutions, some are discarded, others are developed further. The memory embodies these design solutions -sketches, drawings, models, notes, etc.- together with revisions, comments and redlines from the instructors.

Classification is a fundamental capacity of memory. Classification is necessary to retrieve a student's work from the huge quantity of documents created duning the studio. Moreover, classification is necessary to extract semantic information on the progress of the studio as a whole, of students' work and of relationships between the design exercises. Much remains to be done towards the formalization of knowledge in the memory (knowledge bases, object oriented, distributed inference engines\}, the coherence and structuring of the information (e.g. 15010303 STEP, IFC), the polymorphicity on networks of the objects and the constraints and the operators involved (Carrara, Fioravanti \& Novembri, 1998).

\section{Process}

Process refers to the capacity to create, update and modify design, i.e. drawings, models or sketches. In a broader sense, process is the capacity to work with the information during the design studio, not only to elaborate information, but also to communicate and share it.

In the studio information flows are both a structured and a loosely structured process. The revsion process is a structured process, with its distinct steps of presentation of the work, critique and discussion. On the other hand, during a studio there are countless interactions among stu dents and with professors where ideas and suggestions flow freely.

Pedagogically, information process is a methodology and CSDS masters process in addition to content. Methodology offers students lifelong learning skills especially valuable after graduating to cope with continuous innovation.

\section{Collaboration}

The successful interaction between student and instructor relies on collaboration during which principles, values and issues, which emerged during the design process, become a common ground to the group. Students do not make an explicit distinction between working cooperatively or individually. During the studio the information spans the studio horizontally, between students working on a common design theme, and vertically, towards professors. Both information processes are extremely important and CSDS should foster them.

\section{Horizontal Collaboration}

Individual students working on a common design exercise develop different approaches to the same theme. These approaches are partially repetitive, partially overlapping and, sometimes, creative. Altogether they represent the pedagogical experience of the different stu- 


\begin{tabular}{lll}
$\begin{array}{ll}\text { Gianfranco Carrara } \\
\text { Antonio Fioravanti }\end{array}$ & $\begin{array}{l}\text { Pio Luigi Brusasco } \\
\text { Gabriele Novembri }\end{array}$ & Luca Caneparo \\
Anna Maria Zorgno & Computer Supported Design Studio \\
\hline
\end{tabular}

dents. A major contribution of computers in the studios is the sharing of the individual experience among the whole studio-group. A student should able to query the memory of the present or past design studios to obtain other students' design exercises, perhaps with the redlining and comments of the supervising professor.

\section{Vertical Collaboration}

Architectural design is half (this is the half expressed by the noun) a technical task, requiring skill, organizational and managerial ability, and method. The other half, contained in the adjective, is a synthesis and creative work. The educational experience of the design studio is enriched by the contributions of both professors and specialists. The Internet makes it possible to integrate the involvement of specialist knowhow during the appropriate phases of the studio. Constructors, economists, engineers, and eminent professors of heat transmission, energy, transport, illumination, statics, fluid mechanics, electrical engineering, environmental health and geotechnology participate in the studio (cf. Acknowledgements), together with the authors of the present article. This way, the design exercise should be the synthetic view of all aspects of a project (technical, social, organizational, historical, as has been noted by many, from Vitruvius to the present day) on the same level, rather than a point of view strictly limited to one discipline, e.g. engineering.

\section{The system implementation}

When we started the analysis of the CSDS we had in mind certain essential features the system should have: simplicity of use, distributed access and, as the project evolved, flexibility.

\section{Simplicity of use}

The World Wide Web guarantees simplicity of use, because the advent of Web browser technology, such as Netscape Navigator and Microsoft Intemet Explorer has affirmed a common way to access and retrieve information.

\section{Distributed access}

The Web has redefined the meaning of informa tion access and retrieval. People can access information in a transparent way regardless of physical location: they are no longer required to know if a document resides locally or remotely. Through the Web both the students and the professors can easily access the server with the memory of the studio from home or the School. Moreover, they are no longer required to understand or be concerned about the computer they are working on: the last version of their work is accessible from every computer connected to Internet.

\section{Flexibility}

The other important point is flexibility, that is the capacity to work with the presently used applications and data formats, as well as with future ones, not yet foreseen in the initial implementar tion. Flexibility in the processing of different formats of a document is obtained by means of the Multipurpose Internet Mail Extension (MIME) of the Web, which allows the processing of various file formats, hence not only HTML docu ments. This potentiality of the HTTP protocol allows one to associate to each specific file extension the application necessary to visualize, modify, print or save it. The file formats initially recognized as relevant are: AutoCAD, 3D Studio Mox, VRML, Microsoft Word and raster graphics TIFF and JPEG.

\section{Memory implementation}

The computer system supports the students' design work from early analysis phases, through intermediate revision, up to the final presentar tion. The core of the system is the memory (Carrara \& Kalay, 1994), the database, which stores and manages all design documents in the studio.

\section{Memory access}

The access to memory and the overall system is managed by the account-password mechar nism (Fig. 1). The users are clustered in three groups: Professor, Student and Guest. Each group is granted different rights and actions to the documents in the memory. For instance, a user from the Guest group is allowed to browse the documents with "Definitive" status only (cf. Memory structure), and not to take any action on them. 


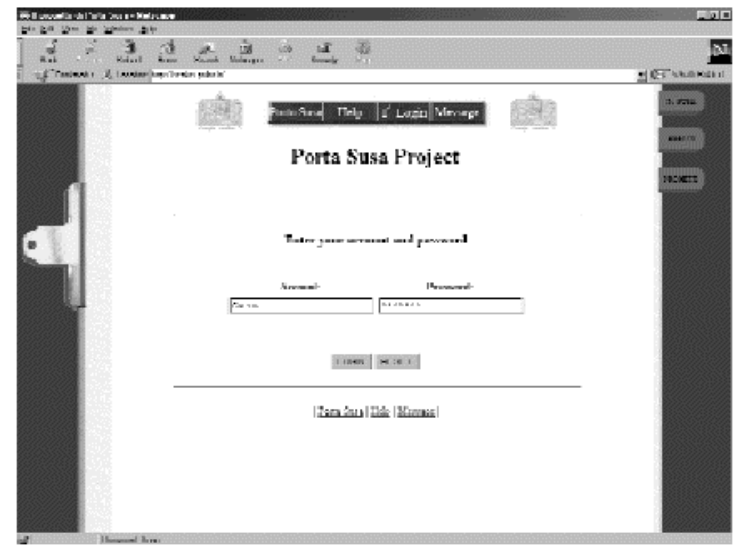

Figure 1. Porta Susa Computer Supported Design Studio Login Screen.
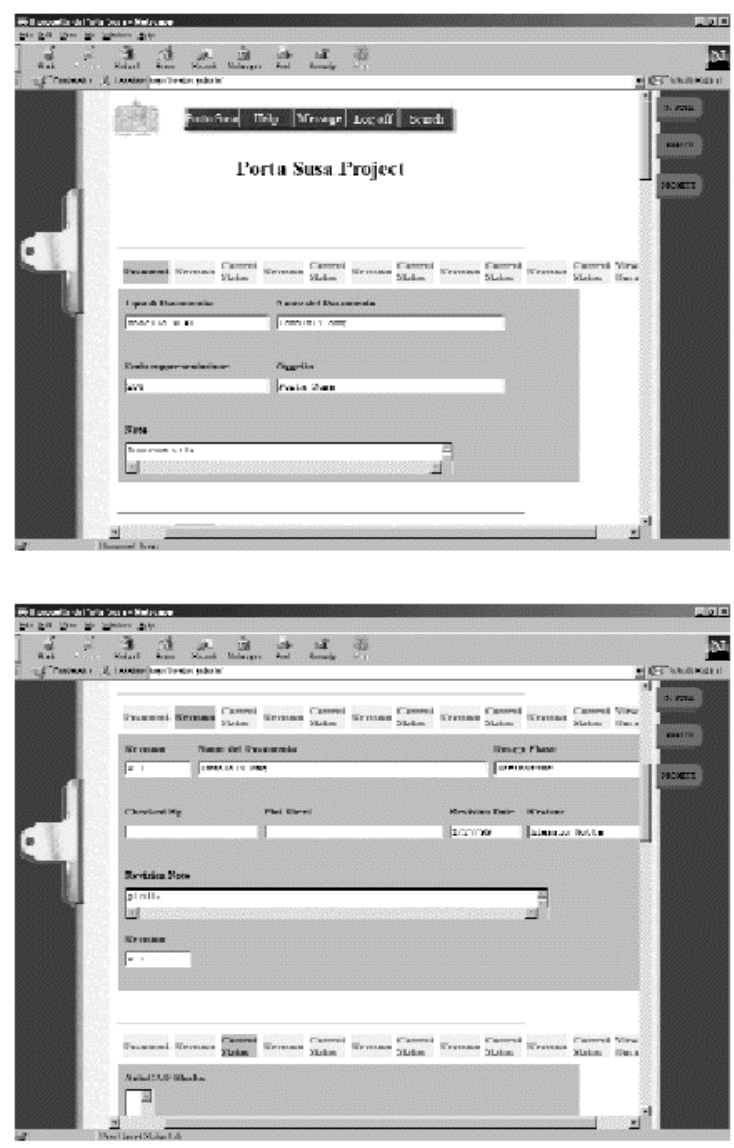

Figure $2 a$ and $b$. The documents stored in the memory are classified according to classes.

\section{Memory Structure}

The structure of memory is cnucial to retrieval and management of documents, especially as the amount stored increases. The documents are stored in the memory according to classes.

When a student creates a new document, s/he is requested to fill in the values for the following classes (Fig. 2):

- Document name. Usually it is the name of the file, but the user is allowed to personalize it.

- Document type. The predefined values are: elevation, correspondence, detail, image, model, plan, plot sheet, report, section, video/animation.

- Scale. The predefined values are: $2000<, 2000$ $500,200,100,50,>50$ and None.

- Design phase. The predefined values are: definitive, design development, program definition, proposal, WWW Internet.

More classes and values can be added, although filling in too many classes can be frustrating and deter from using the system. Further classes are managed by the system automatically:

- Author. The identity of the creator/reviser of the document.

- Date. Date of creation/revision.

- Size. Kb occupied.

- Structure of the document. It enumerates the blocks, chapters or external references, if any.

\section{Process implementation}

To emphasize the evolution of the design process, we distinguish between versions and revisions of the exercises.

A student's design exercise, from inception, goes through various developments. The memory stores all these stages of the design work as versions. If John Doe is a student, his exercise starts 


\begin{tabular}{lll}
$\begin{array}{l}\text { Gianfranco Carrara } \\
\text { Antonio Fioravanti }\end{array}$ & $\begin{array}{l}\text { Pio Luigi Brusasco } \\
\text { Luca Caneparo }\end{array}$ & \\
Gabriele Novembri & Anna Maria Zorgno & Computer Supported Design Studio \\
\hline
\end{tabular}

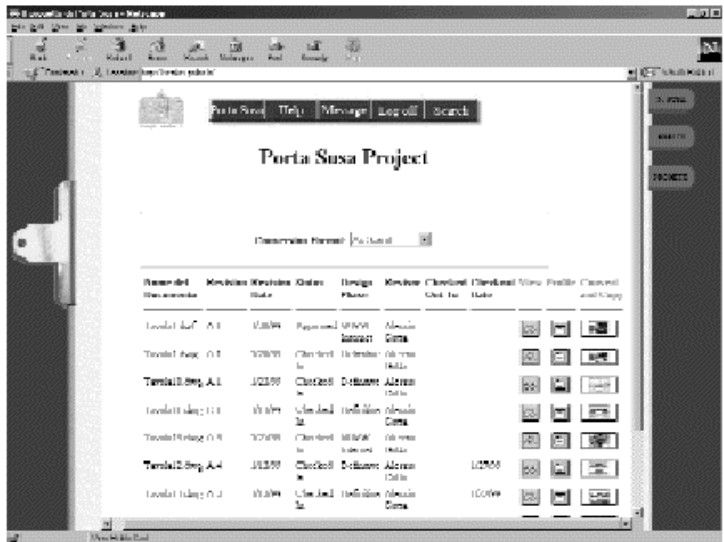

Figure 3. The memory stores the stages of the design work as versions and revisions.

as JohnDoe.A. 1. Further versions of the work are stored with progressive numbers: JohnDoe.A.2, A.3 and so on. Versions are automatically generated and managed by the system when the student saves his work (Fig. 3).

When a student wants to present his work to a professor or a professor defines a deadline to be met, the design exercise goes through a revision. The status of the revision process can be "approved", "incomplete", "incorrect", "reassigned" or "rejected". The revision status is stored with the professor's assessment together with possible comments and redlines. After a revision, the system creates a new version, e.g. JohnDoe.B.1, which can go through the process again, terminating with the final revision and evaluation.

\section{Collaboration implementation}

As considered previously (cf. Collaboration), in the design studio we distinguish between horizontal and vertical collaboration. Horizontal collaboration occurs mainly between students; while vertical is between students and professors.

\section{Horizontal collaboration}

Horizontal collaboration deals with access and cross-reference of information in the design studio. Each student can browse her or his own

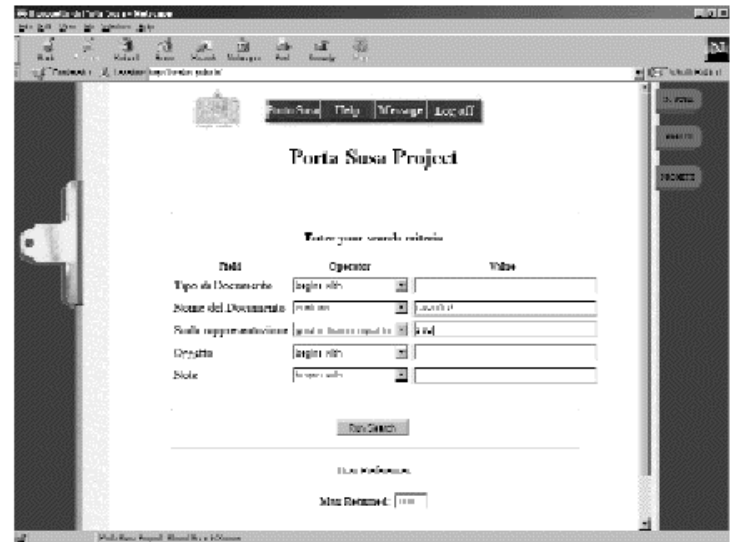

Figure 4. Documents can be retrieved by single- or multifield search criteria.

work and the entire body of the exercises produced during current and past studios. As the amount of browsable information increases, representations to retrieve relevant and pertinent information need to be established.

\section{Queries}

All the search criteria are based on the classes (cf. Memory Structure). Single or bodies of exercises can be retrieved by single- or multi-field search criteria. For instance, can be requested all the documents matching Document name and Scale (Fig. 4).

A more intuitive search method is based on cluster, since it offers a visual approach to search criteria. The system creates and updates clusters of documents according to classes used the most, e.g. Document type vs. Author or Date vs. Scale.

\section{Chronological representations}

The student can revise every stage of the studio according to the various versions and revisions. $\mathrm{S} /$ he can display the professors' comments and redlines associated to the revisions. If s/he decides to elaborate further a previous version, the system generates a new branch with its own sequence of versions (e.g. JohnDoe.A.1/1.1, JohnDoe.A.1/1.2 and so on).

The system associates a thumbnail of the con 
tent of each version and revision stored (Fig. 3 "Convert and Copy" column). The student can go through them and open one by clicking on it: the browser recognizes the file extension and opens the appropriate application (e.g. AutoCAD for drawings).

\section{Relationships between versions and revisions}

This representation visualizes the relationships between students' versions and revisions by means of links. The single versions and revisions are the nodes and the relations connecting them are the arrows. The logical structure of relations is more easily understood as a graph. The graphical representation highlights the organizational structure of the studio and the relations between the documents accessible through the net (Fig. 5). The student or instructor can explore all the phases of the studio observ ing the structure of the arrows, and can browse the interrelated documents by clicking on the nodes.

\section{Vertical collaboration}

Vertical collaboration refers to active management of flows of information between individuals or groups involved in the design studio (Caneparo, 1994). The system implements procedures to route information within users. Information is understood in a broad meaning, as data, documents and messages.

For instance, suppose a student wants a professor to review a design phase: s/he opens a request or message, and writes a note, and associates one or several drawings in the memory.

The system differentiates the flows of information in messages and requests. Messages are informal communication, which do not require a reply. They could be exchanged to keep individual or groups informed. Requests are structured in order to facilitate actions on information. For a request states which they have to go through can be defined. The states are "approved", "incomplete", "incorrect", "reassigned" or "rejected" (cf. Process Implementation). A deadline can be set; in this case the recipient/s are automatically notified of the approaching term.

When the professor logs in, s/he is notified of the request, and is entitled to reply directly to the question. She or he can comment and redline the specified works on-line: the redlining and the notes will be stored in the memory as links to the student's drawings. Otherwise the professor can request a face-to-face meeting in either a physical or virtual place. Virtual places can be desktop videoconferences (Fig. 6) or VRML models of students' exercises.

\section{Shared virtual reality}

Shared Virtual Reality (SVR) (Caneparo, 1997) allows student and professor to enter, "walk in" and 'fly through', a VRML model. Real time visualization of form and space allows the student to "live" the design from visual experience. At the same time, virtual reality lets the student interact immediately with forms in the third dimension, that is, to rethink and modify the model of the design directly.

SVR differs from virtual reality in that the experience of 3D models is no longer individual, but rather is shared among students and professors simultaneously connected across the Internet. As avatars, the students and instructors can meet and communicate with each other whether from a local or remote computer (Fig. 7).

Sharing the same virtual environment among several students and professors offers an innovative educational medium: it is a kind of tour to a virtual building yard, to visualize and experience the on-going stages of the conception and representation of the design exercise.

The tool to gain access through the Internet to SVR environments is a plug-in for the main WWW browsers. The plug-in is automatically loaded when the HTTP protocol defines the VRML format. To the WWW browser the plug-in adds the tools for exploring 3D space, for visualizing other avatars simultaneously connected and for communicating between them. At present the plugin nuns with Windows 95, 98 and NT on Intel CPUs. 


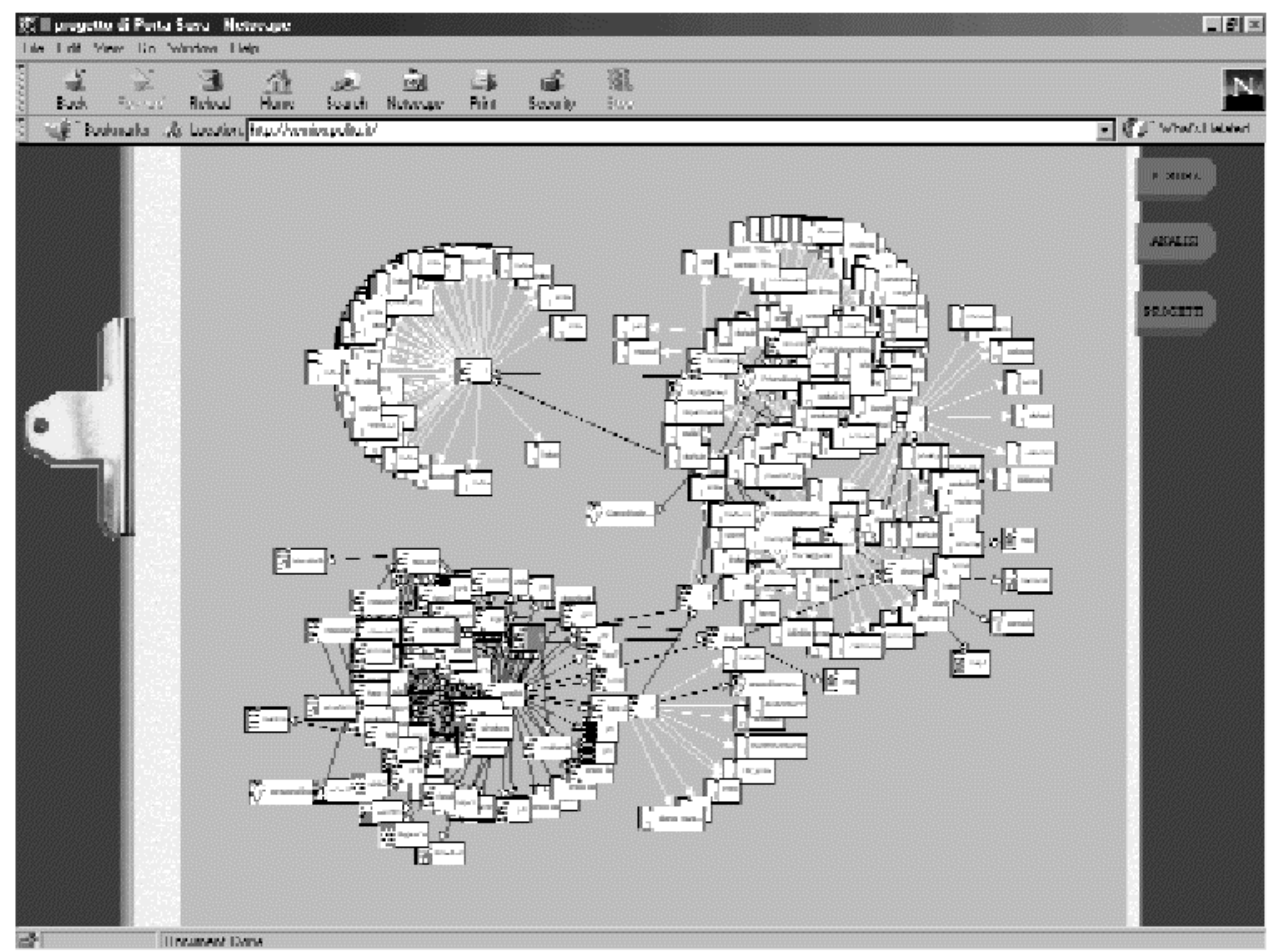

Figure 5. The relationships between versions and revisions are more easily understood graphically as nodes and arrows connecting them.

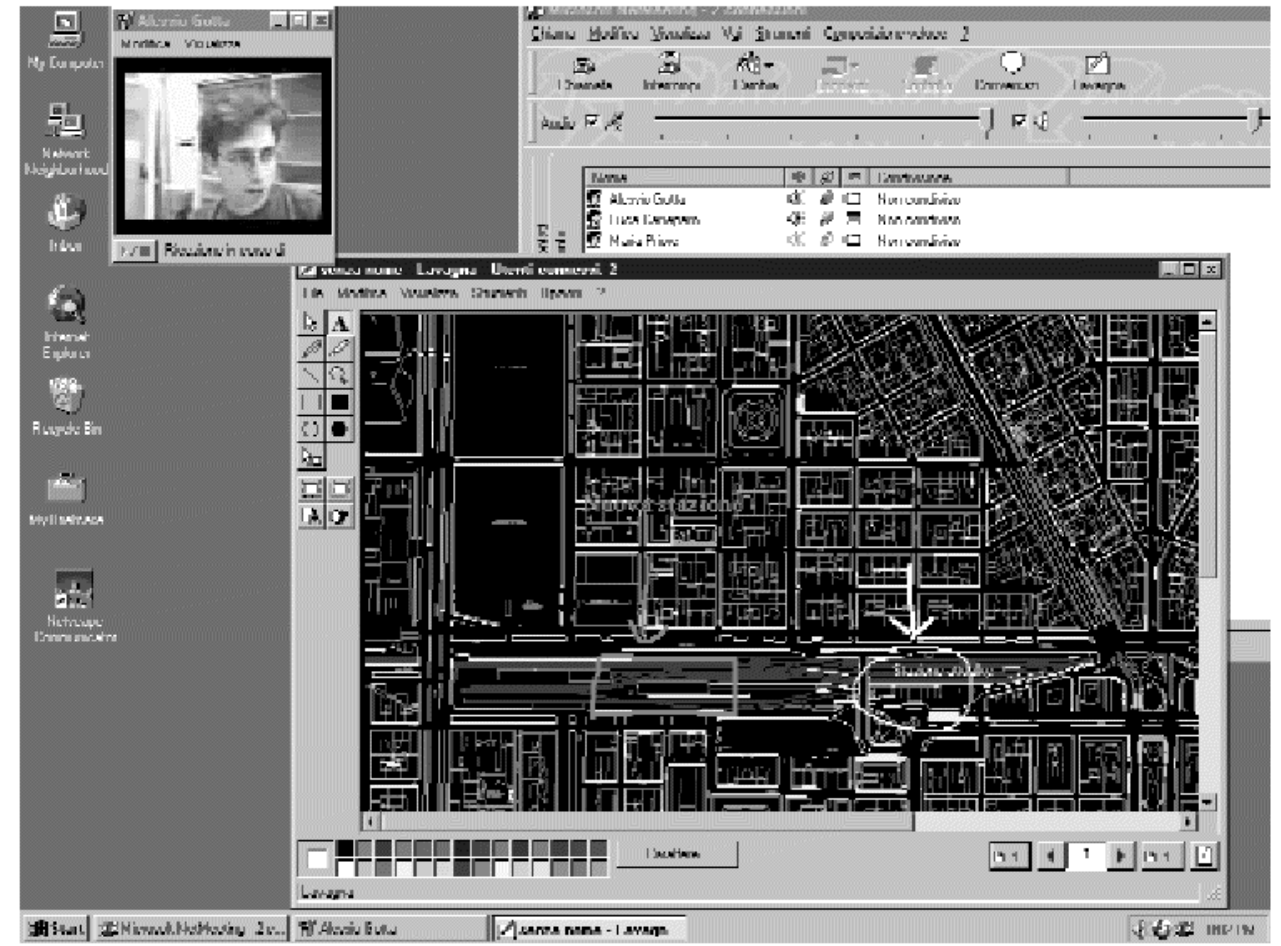

Figure 6. Desktop videoconference and whiteboard of a Porta Susa plan with professor's redlines. 


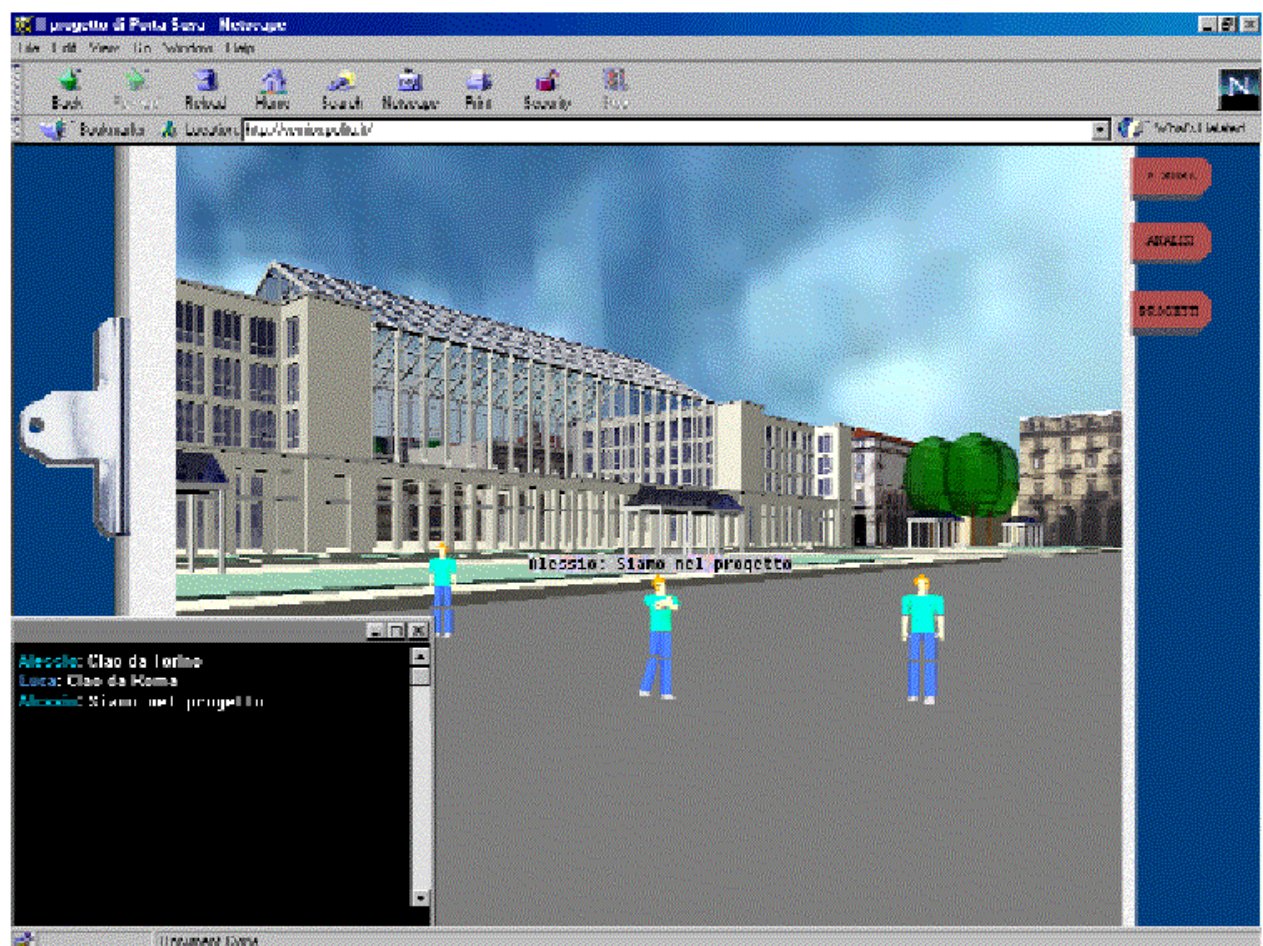

Figure 7. screen shot of a meeting between professors and students in the SVR model of Alessio Gotta's design.

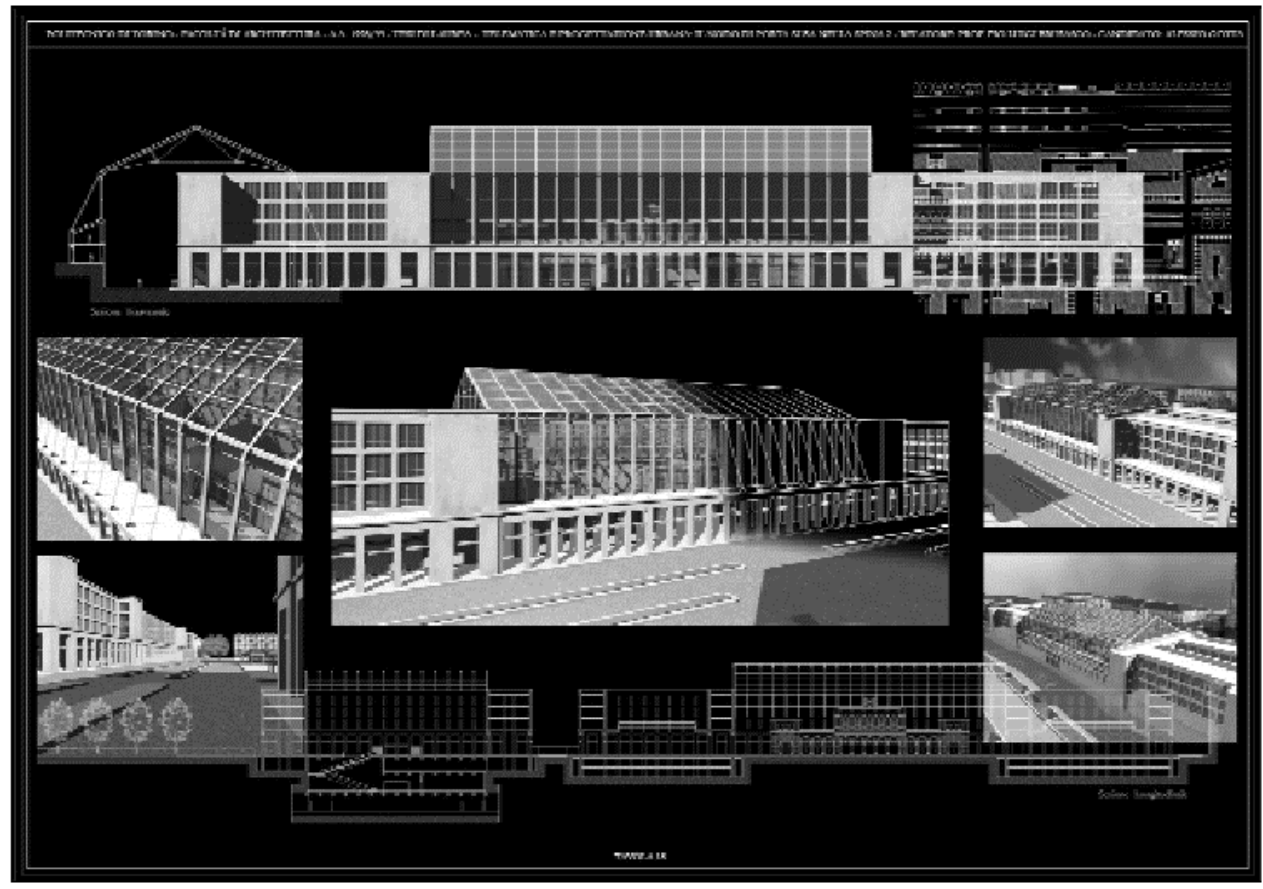

Figure 8. Gotta's final design. Elevations and perspectives of the railway station. 
Gianfranco Carrara

Antonio Fioravanti

Gabriele Novembri
Pio Luigi Brusasco

Luca Caneparo

Anna Maria Zorgno

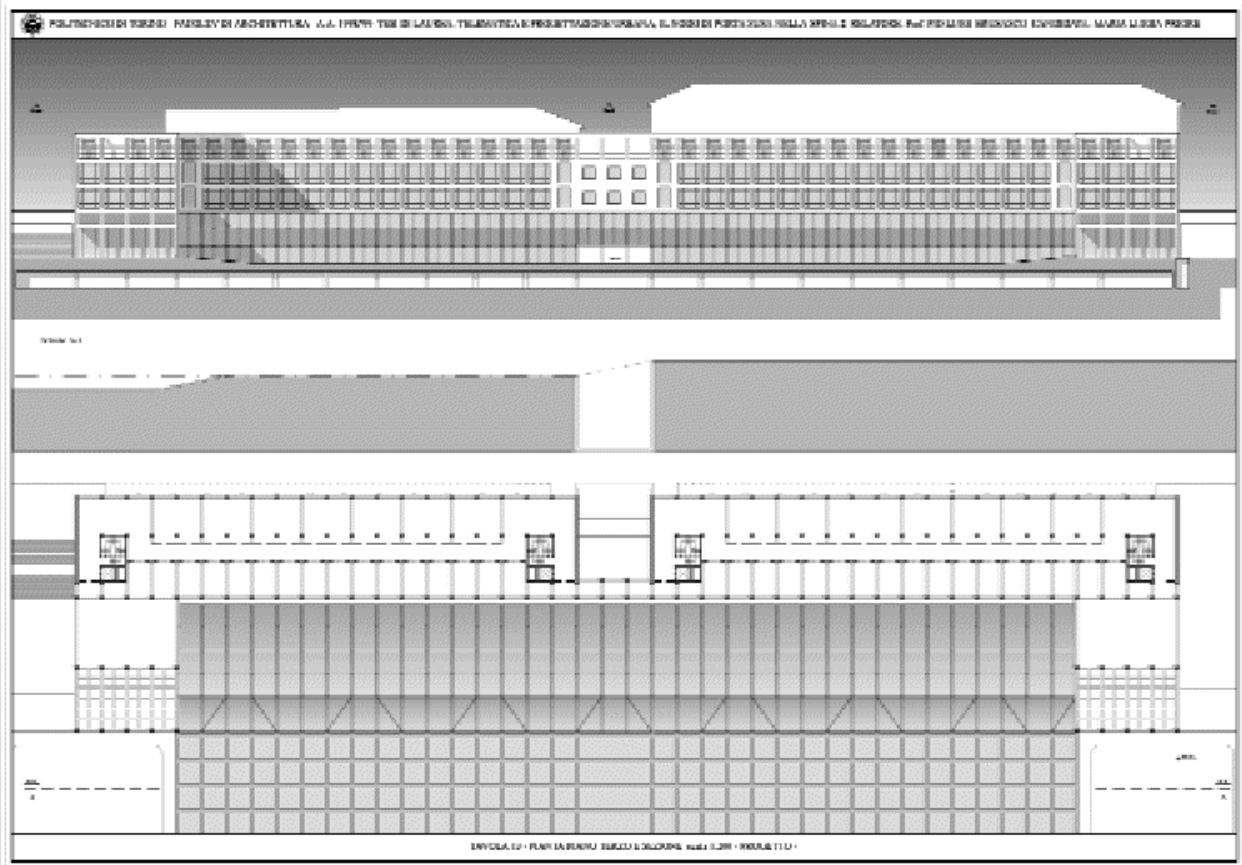

Figure 9a. Priore's final design. Plan and elevation of the railway station.

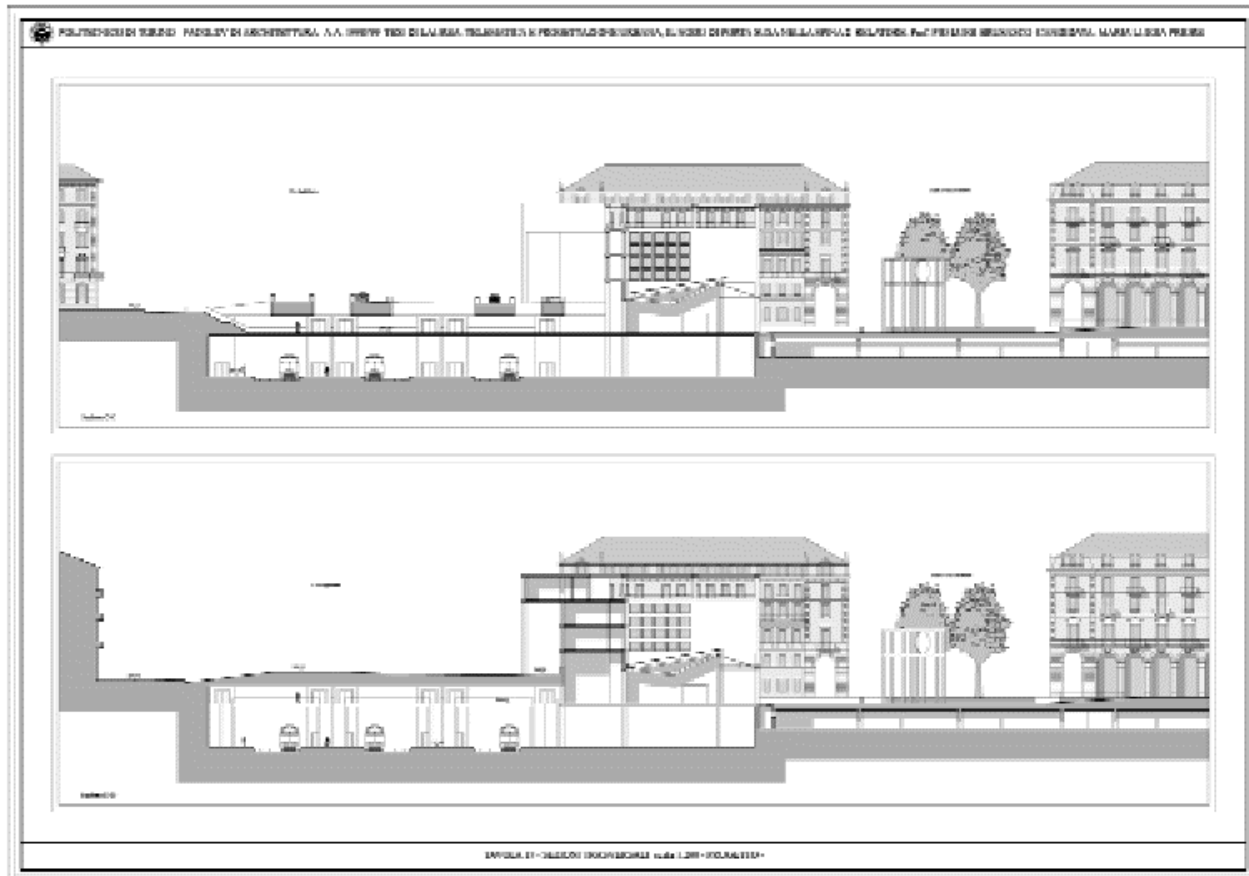

Figure $9 b$. Priore's final design. Cross-sections the railway station and junction. 


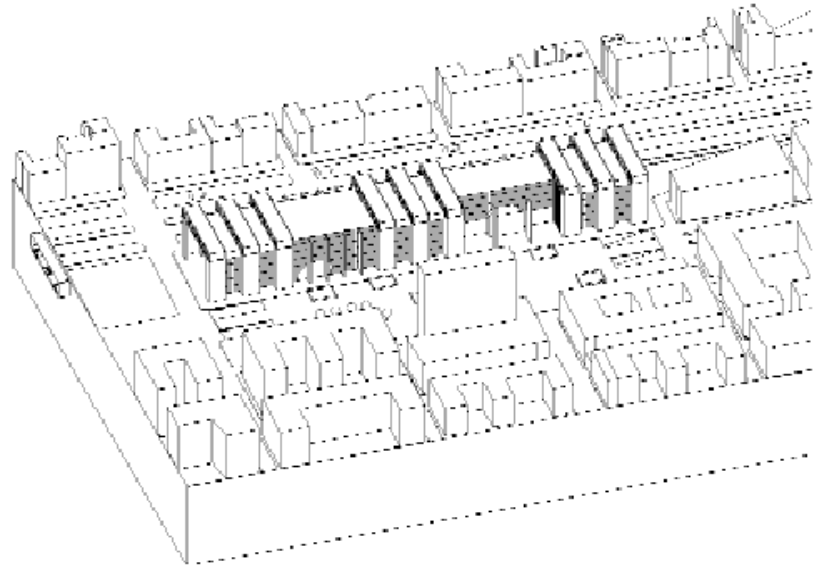

Figure 10. Accorsi's first preliminary project. A row of large tall frames containing all administrative staff offices.

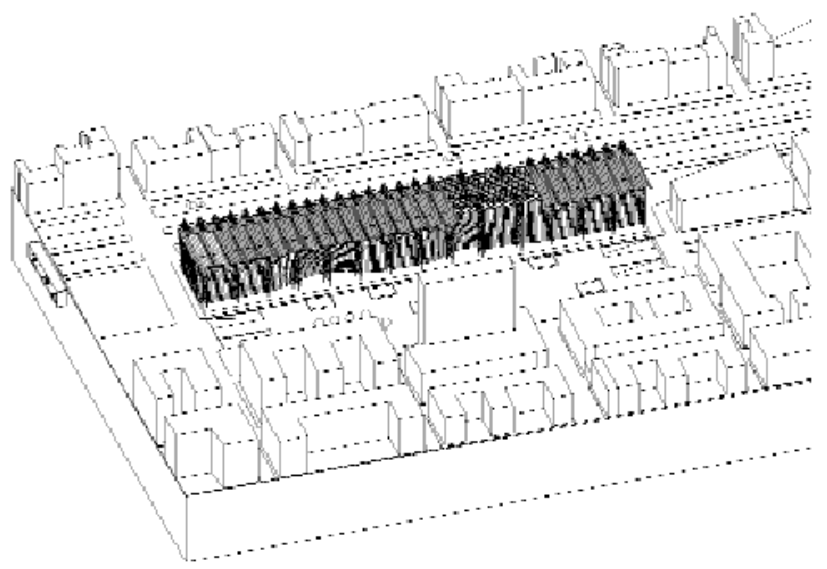

Figure 11. Accorsi's second preliminary project. The roof is built by light barrel vaults, side walls are entirely glassed and receding with respect to the roof.

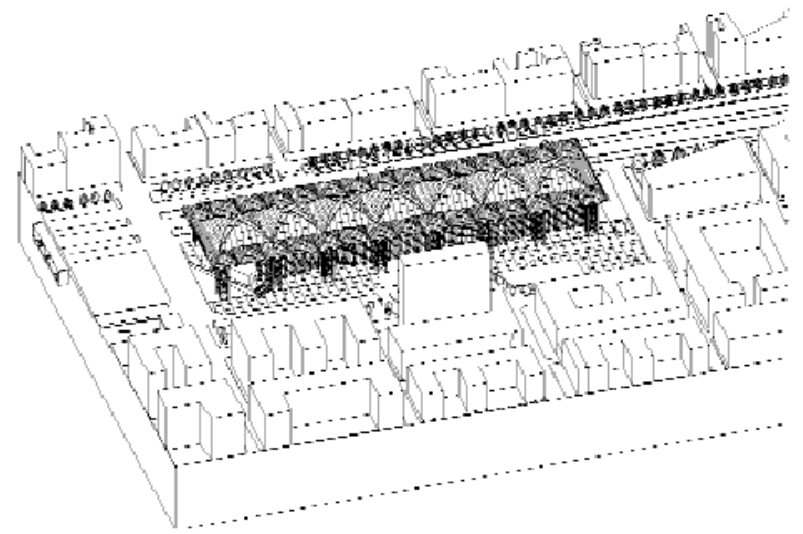

Figure 12. Accorsi's final preliminary project. The roof is
The SVR plug-in integrates a chat program. The chat allows students and instructors in SVR worlds to exchange brief written messages. The plug-in forwards the message to the SVR server, which redistributes it to every user connected. SVR and written chat require really modest Internet bandwidth and so they perform well at $28 \mathrm{k}$ on telephone lines. Vocal messages are supported, which assures more friendly communication. A main drawback of vocal messages is that in the current implementation the communication is not full duplex, a certain time lapse between the submission and the reception exists.

\section{Ongoing experimentation}

1998 is the first academic year the system has been experimented in a design studio. The current experimentation is limited to six students, two at school of Engineering in Rome: Francesco Accorsi and Marco Cruciani; four at the School of Architecture in Turin: Giorgio Emprin, Elena Girotto, Alessio Gotta (Fig. 8) and Maria Luigia Priore (Fig. 9a and b). The on-going CSDS can be accessed on line at http://semios.polito.it/ .

The theme of the design studio is a railway star tion in Turin -Porta Susa- to be incorporated in a reorganized rail transport system (the infrastructures are already under construction) as an intermodal junction between high speed trains, regional trains, direct trains to the airport and the future underground. The fact that this area concerns the ancient city center has considerable impact on the organization of administrative and commercial activities at a regional level, and on real estate values. In particular, the laying and covering (partly completed) of the railway tracks, that split the city in two close to its center, will bring together areas which have developed in separate ways, so creating both potential benefits and potential problems.

The choice of this theme emphasizes the realistic simulation aspects of the studio, where tech nical problems need to be interpreted from an architectural point of view. The design of the new Porta Susa railway station involves historically rich urban context, a complex system of 


\begin{tabular}{lll}
$\begin{array}{ll}\text { Gianfranco Carrara } \\
\text { Antonio Fioravanti }\end{array}$ & $\begin{array}{l}\text { Pio Luigi Brusasco } \\
\text { Gabriele Novembri }\end{array}$ & Luca Caneparo \\
Anna Maria Zorgno & Computer Supported Design Studio \\
\hline
\end{tabular}

city functions and connections and a large number of controlling bodies, who have a decisive role in determining destinations.

\section{A case study}

Francesco Accorsi at the Dipartimento di Architettura e Urbanistica per l'ingegneriab develops the design of a container building acting as the intermodal junction. Accorsi's design exercise exemplifies the inter- and multi-disciplinary methodology carried out in CSDS. The design exercise results as the intersection of different disciplines: architecture, urban planing, structural engineering, energy, geology, fluid mechanics and transport engineering (cf. Acknowledgements).

Architecture. The main idea behind the design is the creation of a large container $(246 \mathrm{~m}$. long, $64 \mathrm{~m}$. wide and $36 \mathrm{~m}$. high) that could house the various previously defined building objects. The old station is preserved as a significant entrance element, although having only the function of ticket office and means of communication with the underlying floors by means of escalators.

In addition to the renovated old railway station, other buildings are required to house restau rants, waiting rooms, luggage deposits, technical premises, staff buildings and lecture rooms because of the greater needs due to the increase in the number of passengers $(16,000$ $\mathrm{p} / \mathrm{h}$ ). Under the square in front of the station a short-term parking station is planned.

Unban planning. The student has decided to separate the three traffic networks (national, regional and metropolitan) completely, locating them underground. In this way the space occupied by the rails is freed and can be used for a rapid transit road, which allows the city to be crossed and two areas that have been separated for nearly a century to be reunited.

Structural. The configuration of the building is determined as though by a set of huge transversely juxtaposed "dolmen" alternating with glass walls. These large tall frames have cross members consisting of reticular beams housing all the administrative staff of the transport com- panies concerned inside them (Fig. 10).

Fluid mechanics specialist interacted during CSDS quantifying prevailing wind loads on the structures and suggesting some projecting parts to be flattened (cf. Fluid mechanics). These parts are formed by the alternation of frames with the rear glassed-in surfaces. The bearing structure is considerably lightened, as it only has to support the roof consisting of a large number of side by side flat roofed barrel vaults. The sidewalls are entirely glassed and receding with respect to the roof alignment in order to reduce solar radiation. The weight of the roof was thus reduced to $65 \mathrm{Kg} / \mathrm{sq} . \mathrm{m}$. (Fig. 11). In order to reduce the weight of the roof even further it is necessary to increase its static efficiency by an improved the design scheme. A change is thus made from barrel vaults on a rectangular base to cloister vaults on a square base, and lastly to vaults pitched over a square base, attaining a weight of $40 \div 50 \mathrm{~kg} / \mathrm{sq} . \mathrm{m}$.

The bearing structure is modified substantially as to its configuration (Fig. 12 and 13). One serious problem is represented by the snow load and was solved by means of placing electrically heated coils on the roof.

Energy. Teflon is used not only for its lightweight but also as it is translucent to the sun's rays, this together with glassed surfaces between the ribs of the pitched vault allows good natural lighting so the use of artificial lighting can be reduced, and energy saving increased.

Fluid mechanics. Prevailing winds are NE and NW blowing at speeds of about $2.5 \div 6.0 \mathrm{~m} / \mathrm{s}$. Aerodynamic tests are being performed in a wind tunnel on scale models of the building in order to check the static safety of the shell and the bearing structure, as well as to determine the internal fluid mechanics.

Geology. The soil is composed of a conglomerate of gravel, sand, traces of mud and clay, limestone concretions, which is strong enough to bear the large frames. It is preferred to transfer the administrative functions to the lower buildings located inside the container. 


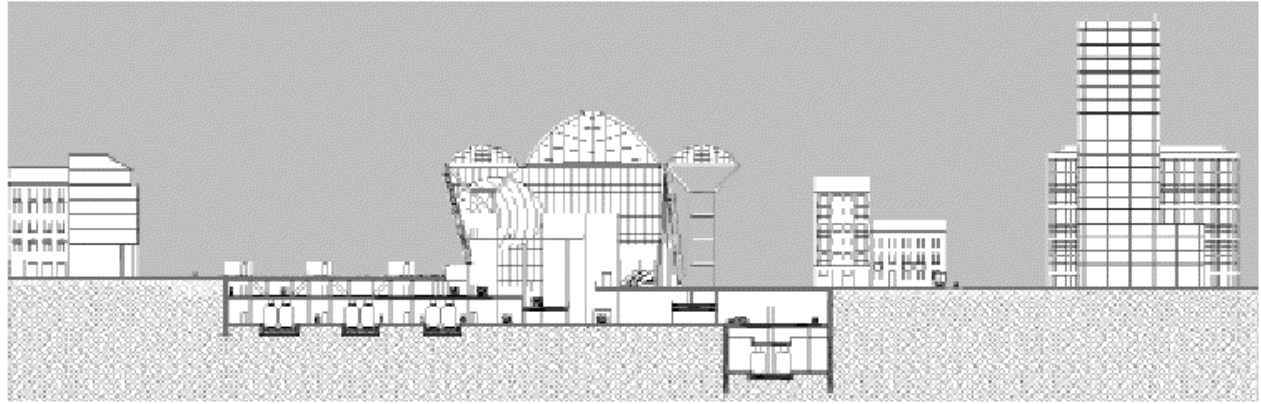

Figure 13. Accorsi's section of final preliminary project. Large canopy vaults cover the old railway station. Underground: on the left the railway, on the right the tube.

\section{Conclusions}

There can be no final word on CSDS, because the experience has been brief and the number of students and design exercises too few.

Conclusions are needed to untie the knot of education in architectural design and in digital media.

The CSDS fosters the students' attitude to digital media for architectural design, and moves towards a paperless design studio. Because the system is friendly ( cf. The System Implementation ), professors prefer to record directly into the system revisions, comments and redlining of students' work. The revision process can be done in a traditional manner (students and instructors meet in the same place): this way the system replaces paper drawings and register books.

CSDS releases participants from the time-place constraint (Mitchell, Davidson \& Wojtowicz, 1992) (Casaus, Cheng, Davidson et al., 1994) (Mitchell, 1995) (Wojtowicz, 1995): at any moment and from every computer in Internet, professors can supervise the design studio.

By means of the collaboration tools (cf. collaboration Implementation), professors can keep informed on the state of the work of the individual students, examine their last version of the work and have an overvew of the previous ones. The memory offers the instructors continuous evaluation of the increments of the individual design exercise, of the responsiveness and creativity in the interaction with the professors and in translating it into design.

Cooperating with the group of professors are specialists from outside the academic world, e.g. from the National Railway Company (cf. A Case Study). Digital media and Internet collaboration fosters the involvement of specialist knowhow at given stages to reply to specific questions, which the students encounter during the studio. The system routes questions and documents to the most qualified person, who not only receives a description of the problem itself, but through horizontal collaboration tools (cf. Horizontal Collaboration) can gain the knowledge of the background where the specific question was raised. This way, the students learn a cooperative methodology in an interdisciplinary envronment, in which they will probably be required to work, after graduating.

A conclusion might be that effective education in digital design media should move from software use teaching towards an integrated use of tools for architectural design purpose. CSDS probably already achieved this goal, because every student participating in the Porta Susa design exercises has shifted her or his attention from the tools themselves to their effective use for architectural design. 


\section{Acknowledgements}

For the collaboration during 1998/1999 CSDS our thanks go to Augusti Giuliano, Professor of Structural Engineering; Cappelli D'Orazio Maria, Professor of Thermotechnics; Cerasoli Sandro, Transport Engineer; D'Amore Marcello, Professor of Electrical Technology and Electromagnetic Fields; Moncada Logiudice Gino, Professor of Energetics; Piva Renzo, Professor of Fluid Mechanics; Veca Giuseppe Maria, Professor of Electrical Technology. For the cooperation our thanks go to Councilor for special projects, Turin Council; State Railway Company; AutoDesk Italia SpA: Kinetix Inc. and to Luca Caneparo for the coordination of the CSDS.

\section{References}

The CSDS is accessible on-line at:

http://semios.polito.it/

Argyris, C. \& Schon, D. (1996). Organizational learning il: theory, method, and practice. Reading, MA: Addison- Wesley.

Cuff, D. (1991). Architecture: the Story of Practice. Cambridge, MA: MIT press.

Caneparo, L. (1994). Groupware and Design Education in Architecture. A. Harfmann \& M. Froser (Eds.), ACADIA '94 (pp. 153-160), St. Lovis: The Association of Computer Aided Design in Architecture.

Caneparo, L. (1997). Shared Virtual Reality for Architectural Design. R. Junge (Ed.), Proceedings of CAAD Futures '97 (pp. 431-442), Dordrecht: Kluwer Scientific Publishing.

Carrara, G. \& Kalay, Y.E. (1994). KnowiedgeBased Computer-Aided Architectural Design. Amsterdam: Elsevier Science B.V.

Carrara, G. Fioravanti, A. \& Novembri, G. (1998). A framework for an Architectural Collaborative Design. Computer craftsmanship in architectural education, Proceedings of 16 th ECAADE Conference, Paris.

Casaus, T., Cheng, N., Davidson, J., Fargas, J., Hubbell, K., Kvan, T., Mitchell, W.J., Nagakura, T.,
Papczian, P., Van Bakergem, D. \& Wojtowicz, J. (1994). Place, Time and the Virtual Design Studio. ACADIA '94 (pp. 115-131), St. Louis: The Association of Computer Aided Design in Architecture.

Mitchell, W.J. (1995). The Future of Virtual Design Studio. J. Wojtowicz (Ed.), Virtual Design Studio (pp. 51-59). Hong Kong: University Press.

Mitchell, W.J., Davidson, J. \& Wojtowicz, J. (1992). Design as correspondence. ACADIA ' 92 (pp. 114-119), Charleston: The Association of Computer Aided Design in Architecture.

Schon, D. (1985). The design studio: an exploration of its traditions and potentials. London: RIBA Publications.

Schon, D. (1987). Educating the Reflective Practitioner. San Francisco, CA: Jossey-Bass Inc. Publishers.

Wojtowicz, J. (Ed.) (1995). Virtual Design Studio. Hong Kong: University Press. 